\title{
Emergency operation for penetrating thoracic trauma in a metropolitan surgical service in South Africa
}

\author{
Damian Luiz Clarke, MMedSci, Muhammed A. Quazi, FRCS, Kriban Reddy, MBBCHB, and \\ Sandie Rutherford Thomson, ChM
}

\begin{abstract}
Introduction: This audit examines our total experience with penetrating thoracic trauma. It reviews all the patients who were brought alive to our surgical service and all who were taken directly to the mortuary. The group of patients who underwent emergency operation for penetrating thoracic trauma is examined in detail.
\end{abstract}

\begin{abstract}
Methodology: A prospective trauma registry is maintained by the Pietermaritzburg Metropolitan Complex. This database was retrospectively interrogated for all patients requiring an emergency thoracic operation for penetrating injury from July 2006 till July 2009. A retrospective review of mortuary data for the same period was undertaken to identify patients with penetrating thoracic trauma who had been taken to the forensic mortuary.
\end{abstract}

\begin{abstract}
Results: Over the 3-year period July 2006 to July 2009, a total of 1186 patients, 77 of whom were female, were admitted to the surgical services in Pietermaritzburg with penetrating thoracic trauma. There were 124 gunshot wounds and 1062 stab wounds. A total of $108(9 \%)$ patients required emergency operation during the period under review. The mechanism of trauma in the operative group was stab wounds $(\mathrm{n}=102)$, gunshot wound $(\mathrm{n}=4)$, stab with compass $(\mathrm{n}=1)$, and impalement by falling on an arrow $(\mathrm{n}=1)$. Over the same period 676 persons with penetrating thoracic trauma were taken to the mortuary. There were $135(20 \%)$ gunshot wounds of the chest in the mortuary cohort. The overall mortality for penetrating thoracic trauma was 541 $(33 \%)$ of 1603 for stab wounds and $135(52 \%)$ of 259 for gunshot wounds of the chest. Among the 541 subjects with stab wounds from the mortuary cohort, there were 206 (38\%) with cardiac injuries. In the emergency operation group there were $11(10 \%)$ deaths. In 76 patients a cardiac injury was identified. The other injuries identified were lung parenchyma bleeding $(n=12)$ intercostal vessels $(n=10)$, great vessels of the chest $(n=6)$, internal thoracic vessel $(n=2)$, and pericardial injury with no myocardial injury $(n=2)$. Most patients reached the hospital within 60 minutes of sustaining their injury. A subset of 12 patients had much longer delays of 12 to 24 hours. Surgical access was via median sternotomy in 56 patients and lateral thoracotomy in 52 . The overall mortality for penetrating cardiac trauma in our series was 217 (76\%) of 282.
\end{abstract}

Conclusions: Penetrating thoracic trauma has a high mortality rate of $30 \%$ for subjects with stab wounds and $52 \%$ for those with gunshot wounds. Less than a quarter of patients with a penetrating cardiac injury reach the hospital alive. Of those who do and who are operated on, about 90 percent will survive. Other injuries necessitating emergency operation are lung parenchyma, intercostal vessels and internal thoracic vessels, and great vessels of the thorax. Gunshot wounds of the thorax remain more lethal than stab wounds. (J Thorac Cardiovasc Surg 2011;142:563-8)

Penetrating thoracic trauma is a common problem in South Africa and is associated with a high mortality rate. ${ }^{1-5}$ This study reviews all penetrating thoracic trauma in a single urban conurbation over a 3-year period by auditing the total number of subjects seen at the 3 government hospitals and a single police mortuary that constitute the Pietermaritzburg Metropolitan Complex. Including the mortuary data allows

From the Metropolitan Trauma Service Pietermaritzburg, Department of General Surgery, Nelson R Mandela School of Medicine, University of Kwa-Zulu Natal, Durban, South Africa.

Disclosures: Authors have nothing to disclose with regard to commercial support.

Received for publication Jan 14, 2011; revisions received Feb 19, 2011; accepted for publication March 18, 2011.

Address for reprints: Damian Luiz Clarke, MMedSci, Department of Surgery, Nelson R. Mandela School of Medicine, University of Kwa-Zulu Natal, Private Bag 7, Congella, 4013, Durban, South Africa (E-mail: nirusha.maharaj@kznhealth.gov.za). $0022-5223 / \$ 36.00$

Copyright (c) 2011 by The American Association for Thoracic Surgery doi:10.1016/j.jtcvs.2011.03.034 for the establishment of an overall mortality rate for penetrating thoracic trauma. Of the subjects with penetrating thoracic trauma who survive to reach the hospital alive, the majority can be managed nonoperatively although a subset of patients require an urgent operation. ${ }^{1,4}$ This study analyzes the subset of patients who required urgent surgery after reaching the hospital alive, reviewing their clinical presentation, operative findings, and clinical outcome.

\section{METHODOLOGY}

The Pietermaritzburg Metropolitan Complex consists of 3 hospitals. There is no specialist thoracic surgical service in the complex and all trauma patients are primarily managed by the general surgical service. For the purposes of this study, penetrating thoracic trauma was defined as a penetrating injury below the clavicles superiorly and above the 


\section{Abbreviations and Acronyms \\ $\mathrm{CT}=$ computed tomogram \\ GSW $=$ gunshot wound \\ $\mathrm{SW}=$ stab wound}

level of the twelfth rib inferiorly. We did not perform emergency room thoracotomy in this series. The logistical constraints in our receiving areas are such that such a procedure is futile and we discourage it. All patients with penetrating thoracic trauma in Pietermaritzburg are assessed by the surgical staff in our receiving departments. Standard resuscitation protocols are followed. We attempt to restrict the volume of fluid administered before the operation, especially if the clinical problem is one of cardiac tamponade. Unstable patients or transient responders are taken directly to the operating theater. We diligently look for signs of cardiac tamponade. A chest radiograph is always obtained where possible. We make liberal use of central venous pressure measurements in patients with suspected cardiac injury. Electrocardiography is performed on an individual basis as an adjunct to clinical assessment. We did not have surgeon-performed ultrasound available during the period of this study. If indicated, we requested a formal radiologist-performed transabdominal ultrasound or a computed tomographic (CT) scan. We do not use chest drain output in isolation as an indication for surgery. We make use of an anterolateral thoracotomy for urgent surgical access and when we are confident that the anticipated injury can be reached through a unilateral incision. If not, we use median sternotomy. We reserve subxiphisternal window for patients who are in stable condition and who have a small pericardial effusion on imaging. We do not perform pericardiocentesis. A prospective trauma registry is maintained by the general surgical service of the Pietermaritzburg Metropolitan Complex. This database is retrospectively interrogated. All patients requiring emergency operation for penetrating thoracic trauma for the period July 2006 till July 2009 were included in this audit. Standard demographic data were recorded. Time from injury to operation as well as physiologic parameters on presentation, clinical findings, and results of radiologic investigations were documented. All operative findings were recorded, including the surgical approach used. A retrospective review of mortuary data for the same period was undertaken to identify patients with penetrating thoracic trauma who had been taken to the forensic mortuary. Data recorded from the mortuary cohort included the mechanism of the penetrating trauma (stab or gunshot) and the injured structure responsible for death (cardiac injury or other injury). The site of retrieval of the corpse was recorded as either a health care facility, implying that the subject reached the hospital with some signs of life, or from the scene, implying that the subject died at the scene.

\section{RESULTS AND FINDINGS \\ Demographics}

Over the 3-year period July 2006 to July 2009, a total of 1186 patients with penetrating chest trauma were admitted to the surgical services in Pietermaritzburg. There were 77 female patients and 1109 male patients in this cohort. The group included $1062(90 \%)$ with stab wounds (SWs) and $124(10 \%)$ with gunshot wounds (GSWs). For the same period, 676 subjects with penetrating thoracic trauma were taken to the mortuary. This is an overall mortality rate of $56 \%$. There were $135 \mathrm{GSWs}$ of the chest and 541 thoracic SWs in the mortuary cohort. This was a statistically significant difference ( $P$ value, .00005$)$. The overall mortality for SWs of the chest is $541(33 \%)$ of 1603 and for GSWs of the chest it is $135(52 \%)$ of 259 . In the hospital cohort, a total of $108(9 \%)$ patients required an emergency operation during the period under review. Tables 1 and 2 summarize the demographic data. The mechanism of trauma in the operative group was SW $(\mathrm{n}=102)$, GSW $(\mathrm{n}=4)$, stab with compass $(\mathrm{n}=1)$, and impalement by falling on an arrow $(\mathrm{n}=1)$.

\section{Clinical Presentation}

Fifty-three patients were in the operating room within 4 hours of sustaining their injury (average, 93 minutes; range, 15-300 minutes). Twelve patients had much longer delays of 12 to 48 hours. All these patients were observed in peripheral hospitals before being transferred to our center. In the remaining patients, the time from incident to definitive management was not recorded. Two patients with cardiac injuries were inappropriately observed in our institution for 4 hours. The reasons for this were multiple torso SWs in 1 and relative stability in the second. Tamponade developed in this patient after 3 hours' observation, with increasing acidosis and distress. At surgery a minor injury to the right atrium was identified. The average systolic blood pressure on presentation was $94 \pm 45 \mathrm{~mm} \mathrm{Hg}$. In 20 patients features of the Beck triad were identified and documented during initial assessment. In all 20, cardiac tamponade was diagnosed at operation. In a single patient with a bleeding lung laceration, the rapid filling of 2 chest drain bottles prompted surgical intervention.

\section{Radiologic Investigation}

Chest radiography was performed in 48 patients. The findings were related to the central mediastinal structures in 25. These included globular heart $(\mathrm{n}=20)$, pneumomediastinum $(\mathrm{n}=3)$, and widened mediastinum $(\mathrm{n}=2)$. Both patients with a widened mediastinum had an aortic injury. In all 23 patients with cardiac abnormalities on radiography, 
TABLE 1. Demographics and overall mortality rates

\begin{tabular}{lcc}
\hline \multicolumn{1}{c}{ PTT (no.) } & SW & GSW \\
\hline Hospital (1186) & $1062(90 \%)$ & $124(10 \%)^{*}$ \\
Mortuary (676) & $541(80 \%)$ & $135(20 \%)^{*}$ \\
Total (hospital and mortuary) & 1603 & 259 \\
Uncorrected $\chi^{2}$ & 32.55 & \\
Total PTT (1862) & 1603 & 259 \\
Overall mortality rates & $541 / 1603(33 \%)$ & $135 / 259(52 \%)$ \\
\hline PTT, Penetrating thoracic trauma; $S W$, stab wound; GSW, gunshot wound. *P \\
value, .00005.
\end{tabular}

cardiac injury was found at operation. The injury was noted to involve the pleural space in 20 cases. These included left hemothorax $(\mathrm{n}=14)$, left pneumothorax $(\mathrm{n}=3)$, and right hemothorax $(\mathrm{n}=3)$. Emergency cardiac ultrasound performed by a radiologist was undertaken in 2 patients and demonstrated a significant pericardial effusion in both. A CT scan was performed in 6 patients and showed a pericardial effusion in 4 and a wall defect in 2 . All patients who had a CT scan arrived 12 hours after the injury and were in hemodynamically stable condition.

\section{Operative Findings}

Surgical access was via median sternotomy in 56 patients and lateral thoracotomy in 52. In 76 patients a cardiac injury was identified. The other injuries identified were lung parenchyma $(n=12)$, bleeding intercostal vessels $(n=10)$, great vessels of the chest $(n=6)$, internal thoracic vessel $(\mathrm{n}=2)$, and pericardial injury with no myocardial injury $(\mathrm{n}=2)$. Table 3 summarizes the operative findings. There were injuries to the right atrium $(\mathrm{n}=3)$, left atrium $(\mathrm{n}=4)$, right ventricle $(\mathrm{n}=38)$, and left ventricle $(\mathrm{n}=31)$. Table 4 summarizes the injuries according to chamber. All of the patients with a delay of 12 hours or greater had superficial myocardial lacerations that had stopped bleeding at the time of operation. They all survived. A single patient had electrocardiographic signs of cardiac ischemia after the ligation of a coronary vessel. He was taken back to the theater where the injury was controlled with a mattress suture, after which the occluding suture was removed. This patient ultimately survived and was discharged from the hospital. An injury to a great vessel of the chest was identified in 6 cases. These vessels included the left subclavian artery $(n=2)$, superior vena cava $(n=2)$, and the aortic arch $(\mathrm{n}=2)$. Other bleeding structures included lung parenchyma $(\mathrm{n}=12)$, intercostal vessels $(n=10)$, internal thoracic vessel $(n=2)$, and a pericardial

TABLE 2. Penetrating thoracic trauma: Hospital cohort

\begin{tabular}{lrc}
\hline \multicolumn{1}{c}{ PTT (no.) } & SW & GSW \\
\hline Hospital (1186) & $1062(90 \%)$ & $124(10 \%)$ \\
Nonoperative (1075) & $958(85 \%)$ & $120(11 \%)$ \\
$*$ Operative (108) & $104(96 \%)$ & $4(4 \%)$ \\
\hline
\end{tabular}

PTT, Penetrating thoracic trauma; $S W$, stab wound; $G S W$, gunshot wound. *Three patients were not included in the data on formal emergency surgery.
TABLE 3. Injuries found at operation

\begin{tabular}{lr}
\hline Cardiac & 76 \\
Lung parenchyma & 12 \\
Intercostal & 10 \\
Great vessels & 6 \\
Internal thoracic & 2 \\
Pericardium & 2 \\
\hline
\end{tabular}

injury with no myocardial injury $(\mathrm{n}=2)$. A single sternotomy incision developed superficial skin sepsis and another broke down, necessitating that the patient be returned to the theater for the incision to be closed. In 2 patients a subxiphoidal exploration was used to exclude cardiac tamponade. These patients are not included in the 108 formal emergency operations.

\section{Mortality}

The overall mortality for penetrating thoracic trauma was $135(52 \%)$ of 259 for GSWs and $541(33.7 \%)$ of 1603 for SWs. In the operative group there were $11(10 \%)$ deaths. Of the 11 patients who died, 3 underwent laparotomy and thoracotomy. In 2 of these there was incorrect sequencing (laparotomy before thoracotomy). The other patient in this subset underwent correct sequencing, but the patient had been inappropriately observed in hospital for 5 hours despite the presence of a persistent acidosis and was only taken for operation when his condition deteriorated dramatically. His death must be attributed to delay in recognition of his condition rather than to the additional laparotomy. All of the deaths occurred in the cardiac injury group. One of the patients who died had a combined cardiac and aortic arch injury. We observed one 5-cm injury to the left atrium, 5 injuries to the left ventricle, and 4 injuries to the right ventricle. All ventricular wounds were large lacerations of 1.5 to $4 \mathrm{~cm}$ in length. One of the patients who died had a delay of 12 hours before arrival at our center and a 2-cm laceration in the right ventricle. In the SW subset from the mortuary cohort, 206 cardiac injuries were identified. Of the 206 patients with cardiac injuries identified at the mortuary, 27 initially were taken to a hospital alive but died without the being operated on. These hospitals were all outside the 3 hospitals in the metropolitan complex. The overall mortality for penetrating cardiac trauma is 217 $(76 \%)$ of 282 .

\section{DISCUSSION}

The etiology of penetrating thoracic trauma in Kwa-Zulu Natal has continued to evolve over the past 2 decades. In the

TABLE 4. Injury per cardiac chamber

\begin{tabular}{lr}
\hline Right atrium & 3 \\
Left atrium & 4 \\
Right ventricle & 38 \\
Left ventricle & 31 \\
\hline
\end{tabular}


early 1990s, a dramatic increase in GSWs was noted over a relatively short period of time. A large forensic and hospital study from Durban found that GSWs increased from $34 \%$ of all thoracic injuries in 1990 to $50 \% 2$ years later. ${ }^{2}$ Although the total number of hospital admissions had not changed over a decade, there had been significant changes in the modality of injury. SWs declined by one third whereas GSWs increased by more than $800 \%$. The increased severity of GSWs was evidenced by the observation that direct admission to the mortuary was 3 times as common in cases of GSW compared with SW. The hospital mortality rate for GSWs was 8 times that for SWs. This dramatic increase was also commented on in a study comparing hospital admissions with mortuary data for penetrating cardiac injury in Durban over the same period. ${ }^{3}$ The exceptionally high incidence of GSWs documented in these 2 studies seems to have declined somewhat in the intervening 15 years. In a 1-year audit of thoracic trauma from Durban in the year 2000, thoracic GSWs comprised only about $20 \%$ of admissions for thoracic trauma. ${ }^{4}$ We had a low incidence of GSWs (10\%) compared with SWs in our operative series. It would appear that the incidence of GSW, albeit still high, has stabilized in our environment and the extraordinarily high incidence seen in the early 1990s has dramatically decreased. However, the increased severity of GSW of the chest is demonstrated by the fact that in our mortuary data the proportion of GSWs $(20 \%)$ was double that in the hospital group $(10 \%)$. The overall mortality rate for penetrating thoracic trauma remains high. For SWs it is in the order of one third, and just over half of the subjects with thoracic GSWs die (Tables 1 and 2).

The average time from incident to operative intervention in this series is $1 \frac{1 / 2}{2}$ hours. Once at our center, our receiving staff are familiar with the problem. However, even relatively experienced staff can be misled. Two patients with cardiac injury were inappropriately observed in our institution for 4 and 5 hours, respectively, before operative intervention was instituted. This delay resulted in the death of 1 of these patients.

Penetrating cardiac trauma has a reported mortality rate of $40 \%$ to $90 \%{ }^{3,6-15}$ Hospital-based studies are biased inasmuch as they tend to ignore mortuary data. Our results confirm this with stabbed hearts from the mortuary cohort outnumbering those from the hospital cohort by two thirds. Earlier postmortem data from our institution suggested that even this ratio may be optimistic. ${ }^{3}$ Establishing the diagnosis of a penetrating cardiac wound may be difficult and the diagnosis may be missed entirely. ${ }^{3}$ In our mortuary series about $14 \%$ of patients with cardiac injuries had died in a hospital without the diagnosis being made. Patients with a penetrating cardiac injury may fall into 1 of 3 groups. ${ }^{13,14}$ The patient in extremis, the partially compensated transient responder, or the relatively asymptomatic patient with an SW to the precordium. Patients who are in extremis may benefit from an emergency department thoracotomy. Logistically, emergency department thoracotomy is very difficult in our environment and we do not encourage it. In the absence of surgeon-performed cardiac ultrasound, our assessment of penetrating thoracic trauma remains by necessity clinical. We look for features of cardiac tamponade. These features may not be present or may be difficult to elicit. In only $20(29 \%)$ of our series was a firm diagnosis of cardiac tamponade recorded. However, when present, we found it to be highly predictive of cardiac tamponade. ${ }^{13,14}$ Our indications for operation are ongoing hemodynamic instability and acidosis with or without the presence of clinical features of cardiac tamponade.

We obtained a chest radiograph in just under half of our cohort. The chest radiograph demonstrated a cardiac injury in 25 patients. In each of these patients cardiac or pericardial injury was confirmed at operation. This suggests that cardiac abnormalities on chest $\mathrm{x}$-ray films are suggestive of penetrating cardiac injury. In the remainder, the injury demonstrated on the chest $\mathrm{x}$-ray film involved the pleural space. The presence of mediastinal widening rather than a globular heart should raise the suspicion of a mediastinal injury, rather than a cardiac injury. We had 2 patients with mediastinal widening and both had a great vessel injury. We have found the strain patterns seen on electrocardiography to be nonspecific. In the absence of signs of cardiac tamponade, our most common indication for operative exploration was ongoing hemodynamic instability. Chest drain output is not a reliable sign. ${ }^{15}$ Chest drains may be blocked or badly positioned. Chest drain output must be interpreted in conjunction with the overall clinical picture.

If the clinical findings are equivocal and the patient remains in hemodynamically stable condition, a number of diagnostic modalities may be helpful. ${ }^{16-24}$ For an investigation to be of benefit it must be readily available on demand, noninvasive, mobile, repeatable, and accurate. Surgeon-performed ultrasound meets these criteria. We performed cardiac ultrasound in 2 patients and this confirmed pericardial fluid in both cases. ${ }^{16,17}$ The fact that 2 patients with a cardiac injury were inappropriately observed for over 4 hours in our institution highlights the need for surgeon-performed cardiac ultrasound. ${ }^{16-19}$ In stable patients who arrive several hours after injury, CT scan will demonstrate blood in the pericardial sac. ${ }^{20}$ We performed CT scan in 6 patients. Once CT scan confirmed pericardial fluid, we subjected all of these patients to formal operative exploration and drainage. All of these patients had minor cardiac injuries that had stopped bleeding by the time they were brought to our center. This is the group that may be suitable for a more conservative management approach. The use of a subxiphoidal exploration to exclude hemopericardium has been advocated in other regions but has traditionally been viewed with a degree of skepticism in South Africa. ${ }^{5,7,15,22-26}$ Recently, the Cape Town group 
published their experience with the use of subxiphoidal exploration and drainage alone in patients with minor grades of myocardial injury who arrived for treatment several hours after the injury. ${ }^{25,26}$ Thoracoscopic assessment has also been used in this subset of patients. ${ }^{25,26}$

The anatomy of the heart determines the likelihood of chamber injury. ${ }^{14}$ The literature reports that the right and left ventricles are injured $43 \%$ and $33 \%$ of the time, respectively, whereas for the atria right-sided injuries are seen in $14 \%$ and left-sided lesions in $5 \%$ of cases. Great vessel injuries occur in $5 \%$ of cases. ${ }^{10,13,14}$ Our own experience is very much in keeping with these reported findings. Injury to the lung parenchyma is the next most common source of bleeding, followed by internal thoracic or intercostal vessel bleeding. Injury to the great vessels of the thorax is not common in hospital-based studies inasmuch as only minor injuries to these vessels are usually compatible with survival. ${ }^{27-29}$ Less than a third of patients with a penetrating cardiac injury will reach our center alive. Our mortality rate $(10 \%)$ for penetrating cardiac trauma treated surgically compares favorably with the reported mortality rates from overseas centers of under $9 \%$ for all cardiac injuries. ${ }^{6,7-14}$ The deaths in our operative group series were all from cardiac injury. Delay in making the diagnosis was a major contributing factor in 2 of the 11 deaths. Large lacerations with pleural breech were also associated with mortality, as were combined cardiac and aortic injury.

The decision as to which surgical approach to use depends on the mechanism of trauma, the site of the wounds, and the expected injuries. ${ }^{29}$ Median sternotomy is more difficult to perform than a lateral incision and more difficult to close. Sternal sepsis after such an emergency approach is a consideration. We had a single incision in which superficial skin sepsis developed and another that broke down and required a return to the theater for closure. However, median sternotomy gives excellent exposure to the anterior mediastinal structures. Access to the aortic arch is limited by a lateral thoracotomy. We advocate median sternotomy for all parasternal stab wounds and in cases in which there is the potential for an injury to the great vessels. If the wound is more peripheral or if absolutely urgent access is needed, an anterolateral thoracotomy through the fourth or fifth intercostal space is easy to perform and provides adequate exposure. We do not have access to cardiopulmonary bypass or to a dedicated specialist cardiothoracic service at our center. Although complex cardiac injuries may require cardiopulmonary bypass, long delays in transportation to the hospital mean that it is unlikely that persons with such complex injuries would reach our center alive.

\section{CONCLUSIONS}

Penetrating thoracic trauma remains a common problem with a high mortality rate. Although the incidence of GSWs has declined somewhat, they remain much more lethal than
SWs. The vast majority of patients with penetrating thoracic trauma who survive to reach the hospital alive can be managed nonoperatively. In $10 \%$ of cases emergency operation is necessary. The most common injury to necessitate an emergency operation after penetrating thoracic trauma is a cardiac injury. In our environment, less than one third of patients with a penetrating cardiac injury will reach the hospital alive. If they are operated on, the survival is in the order of $90 \%$. Delays and large lacerations with pleural breech are associated with mortality. In about a third of cases the injury necessitating operative intervention is not a cardiac injury. These injuries are usually easily dealt with by ligation or suturing. Occasionally, cervicomediastinal and thoracic inlet vascular injuries may require complex repair. Surgeon-performed sonar may facilitate the diagnosis of cardiac tamponade and holds great promise. It needs to be introduced at our center. The role of conservative management of minor grades of cardiac injury awaits further clarification.

\section{References}

1. Muckart DJ, Luvuno FM, Baker LW. Penetrating injuries of the pleural cavity. Thorax. 1984;39:789-93.

2. Muckart DJ, Meumann C, Botha JB. The changing pattern of penetrating torso trauma in KwaZulu/Natal-a clinical and pathological review. S Afr Med J. 1995;85:1172-4

3. Campbell NC, Thomson SR, Muckart DJ, Meumann CM, Van Middelkoop I, Botha JB. Review of 1198 cases of penetrating cardiac trauma. Br J Surg. 1997;84:1737-40.

4. Madiba TE, Thomson SR, Mdlalose N. Penetrating chest injuries in the firearm era. Injury. 2001;32:13.

5. von Oppell UO, Bautz P, De Groot M. Penetrating thoracic injuries: what we have learnt. Thorac Cardiovasc Surg. 2000;48:55-61.

6. Kish G, Kozloff L, Joseph WL, Adkins PC. Indications for early thoracotomy in the management of chest trauma. Ann Thorac Surg. 1976;22:23-8.

7. Demetriades D, van der Veen BW. Penetrating injuries of the heart: experience over two years in South Africa. J Trauma. 1983;23:1034-41.

8. Asensio JA, Soto SN, Forno W, Roldan G, Petrone P, Salim A, et al. Penetrating cardiac injuries: a complex challenge. Injury. 2001;32:533-43.

9. Asensio JA, Berne JD, Demetriades D, Chan L, Murray J, Falabella A, et al. One hundred five penetrating cardiac injuries: a 2-year prospective evaluation. $J$ Trauma. 1998;44:1073-82.

10. Thourani VH, Feliciano DV, Cooper WA, Brady KM, Adams AB, Rozycki GS et al. Penetrating cardiac trauma at an urban trauma center: a 22-year perspective. Am Surg. 1999;65:811-6.

11. Degiannis E, Loogna P, Doll D, Bonanno F, Bowley DM, Smith MD. Penetrating cardiac injuries: recent experience in South Africa. World J Surg. 2006;30: 1258-64.

12. Gao JM, Gao YH, Wei GB, Liu GL, Tian XY, Hu P, et al. Penetrating cardiac wounds: principles for surgical management. World J Surg. 2004;28:1025-9.

13. Asensio JA, Stewart BM, Murray J, Fox AH, Falabella A, Gomez H, et al. Penetrating cardiac injuries. Surg Clin North Am. 1996;76:685-724.

14. Asensio JA, Murray J, Demetriades D, Berne J, Cornwell E, Velmahos G, et al Penetrating cardiac injuries: a prospective study of variables predicting outcomes. J Am Coll Surg. 1998;186:24-34.

15. Demetriades D, Rabinowitz B, Markides N. Indications for thoracotomy in stab injuries of the chest: a prospective study of 543 patients. Br J Surg. 1986;73: 888-90.

16. Shanmuganathan K, Matsumoto J. Imaging of penetrating chest trauma. Radiol Clin North Am. 2006;44:225-38, viii.

17. Patel AN, Brennig C, Cotner J, Lovitt MA, Foreman ML, Wood RE, et al. Successful diagnosis of penetrating cardiac injury using surgeon-performed sonog raphy. Ann Thorac Surg. 2003;76:2043-6.

18. Nagy KK, Lohmann C, Kim DO, Barrett J. Role of echocardiography in the diagnosis of occult penetrating cardiac injury. J Trauma. 1995;38:859-62. 
19. Aaland MO, Bryan FC 3rd, Sherman R. Two-dimensional echocardiogram in hemodynamically stable victims of penetrating precordial trauma. Am Surg. 1994; 60:412-5.

20. Nagy KK, Gilkey SH, Roberts RR, Fildes JJ, Barrett J. Computed tomography screens stable patients at risk for penetrating cardiac injury. Acad Emerg Med. 1996;3:1024-7.

21. Brewster SA, Thirlby RC, Snyder WH 3rd. Subxiphoid pericardial window and penetrating cardiac trauma. Arch Surg. 1988;123:937-41.

22. Andrade-Alegre R, Mon L. Subxiphoid pericardial window in the diagnosis of penetrating cardiac trauma. Ann Thorac Surg. 1994;58:1139-41.

23. Miller FB, Bond SJ, Shumate CR, Polk HC Jr, Richardson JD. Diagnostic pericardial window. A safe alternative to exploratory thoracotomy for suspected heart injuries. Arch Surg. 1987;122:605-9.
24. Morales CH, Salinas CM, Henao CA, Patiño PA, Muñoz CM. Thoracoscopic pericardial window and penetrating cardiac trauma. J Trauma. 1997;42:273-5.

25. Navsaria PH, Nicol AJ. Video-assisted thoracoscopic pericardial window for penetrating cardiac trauma. S Afr J Surg. 2006;44:18-20.

26. Navsaria PH, Nicol AJ. Haemopericardium in stable patients after penetrating injury: is subxiphoid pericardial window and drainage enough? A prospective study. Injury. 2005;36:745-50.

27. Robbs JV, Reddy E. Management options for penetrating injuries to the great veins of the neck and superior mediastinum. Surg Gynecol Obstet. 1987;165:323-6.

28. Nair R, Robbs JV, Muckart DJ. Management of penetrating cervicomediastinal venous trauma. Eur J Vasc Endovasc Surg. 2000;19:65-9.

29. Navid F, Gleason TG. Great vessel and cardiac trauma; diagnostic and management strategies. Semin Thorac Cardiovasc Surg. 2008;20:31-8. 